\title{
Fazer teatro na Hungria A alternativa dos Pintér Béla e Companhia
}

\section{Mónika Bense}

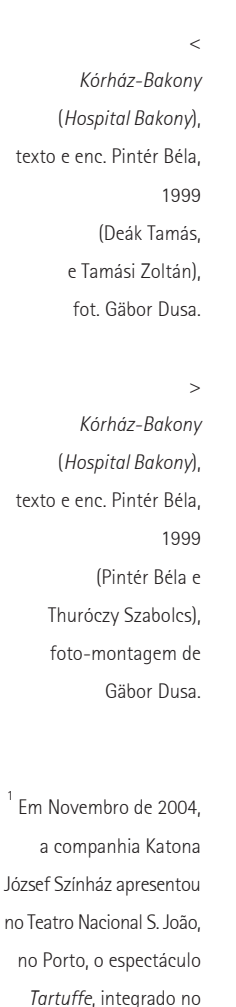

PoNTI. Uma breve

referência a este

espectáculo encontra-se

no artigo "PoNTI' 04 / XIII

UTE", da autoria de

Alexandra Moreira da Silva

e Paulo Eduardo Carvalho

em Sinais de cena, n. 2,

Dezembro de 2004,

pp. 106-107.

A companhia

apresentou-se em Lisboa,

no Grande Auditório da

Culturgest, a 13 de Janeiro

de 2005 com o espectáculo

Siráj (A gaivota).

${ }^{3}$ Uma das particularidades

da lingua húngara é a

inversão do nome:

primeiro vem o apelido,

depois o nome próprio.

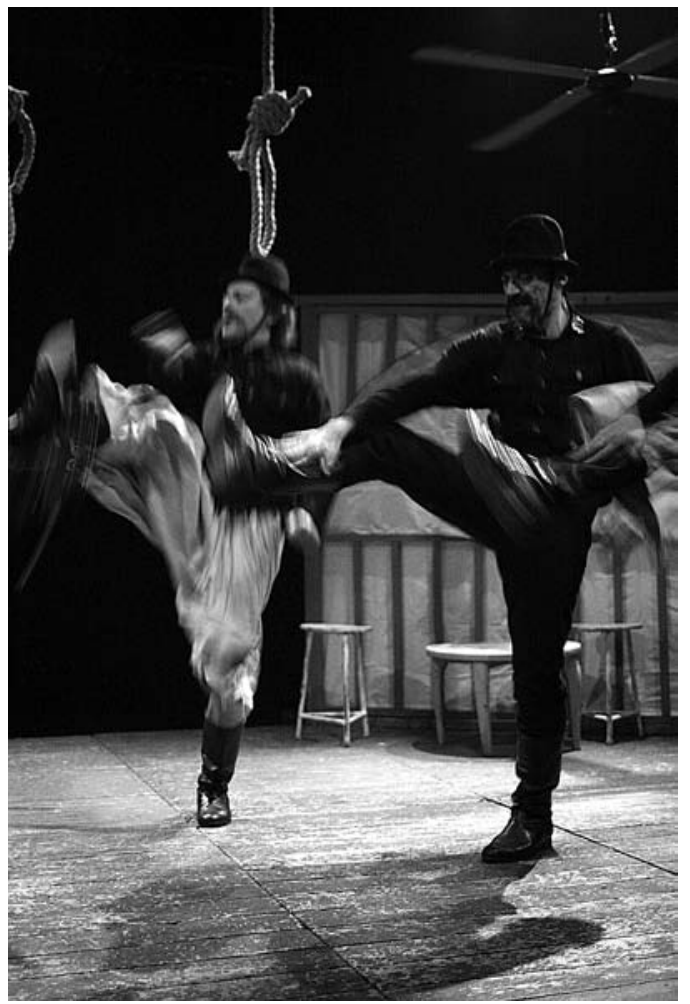

0 teatro húngaro não é totalmente desconhecido em Portugal. Basta pensar no Teatro Katona József ${ }^{1}$ e nos Krétakör ${ }^{2}$ que, a meu ver, bastariam para provar que vale a pena dar mais atenção ao teatro que se vem fazendo neste país do Leste europeu.

O grupo Pintér Béla e Companhia é considerado um dos teatros mais inovadores na Hungria. 0 objectivo dos artistas que o compõem é criar peças de teatro

contemporâneas, baseadas na observação profundamente crítica e, ao mesmo tempo, fortemente irónica da sociedade, aí incluindo a própria personalidade dos seus criadores. De entre os processos usados contam-se a sobreposição irónica da realidade e do surreal, do autêntico e do pastiche, do folclore húngaro e do kitsch. A originalidade das suas ideias fez deles uma das companhias mais relevantes do pais.

0 dramaturgo inglês David Hare escreveu com grande entusiasmo sobre Harold Pinter, declarando que, sempre que se senta para ver uma peça de Pinter não sabe o que Ihe vai acontecer nas 2-3 horas seguintes. Se calhar esta coincidência de apelidos ${ }^{3}$ não é um acaso, e o teatro experimental húngaro de Pintér Béla, dramaturgo,

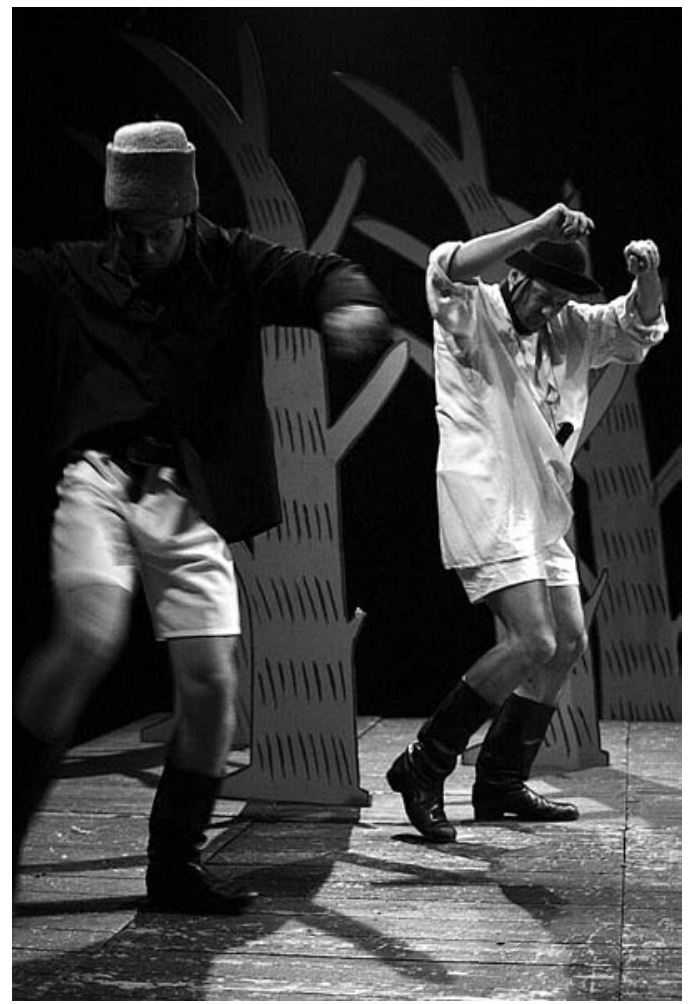

encenador e actor, é tão único no seu género na Hungria como o "fenómeno Harold Pinter" na Grã-Bretanha.

0 Pintér húngaro procura obsessivamente novos caminhos, fórmulas da interpretação e, no meio teatral húngaro, é considerado acima de tudo o mais original fazedor de teatro.

Na Hungria, este tipo de teatro criado por uma pessoa, centrado numa figura carismática, é uma raridade. Pintér encena unicamente as suas peças e desempenha papéis principais nos espectáculos que cria a partir delas. Sem ter uma formação profissional específica em teatro, é um autodidacta que fundou a sua própria companhia em 1998 e, a partir daí, todos os anos estreia um novo espectáculo. A Pintér Béla e Companhia reconhece-se como teatro "alternativo", de sentido experimental, o que os diferencia do teatro "de pedra", ou seja, dos teatros oficiais. Esta diferença resulta dos dois tipos de financiamento estatal que encontramos na Hungria: um que é aplicado no teatro mais "institucional" (atribuido anualmente sem necessidade de concurso) e outro que abrange os grupos experimentais (sujeito a concurso anual) sendo este significativamente mais modesto e obedecendo 


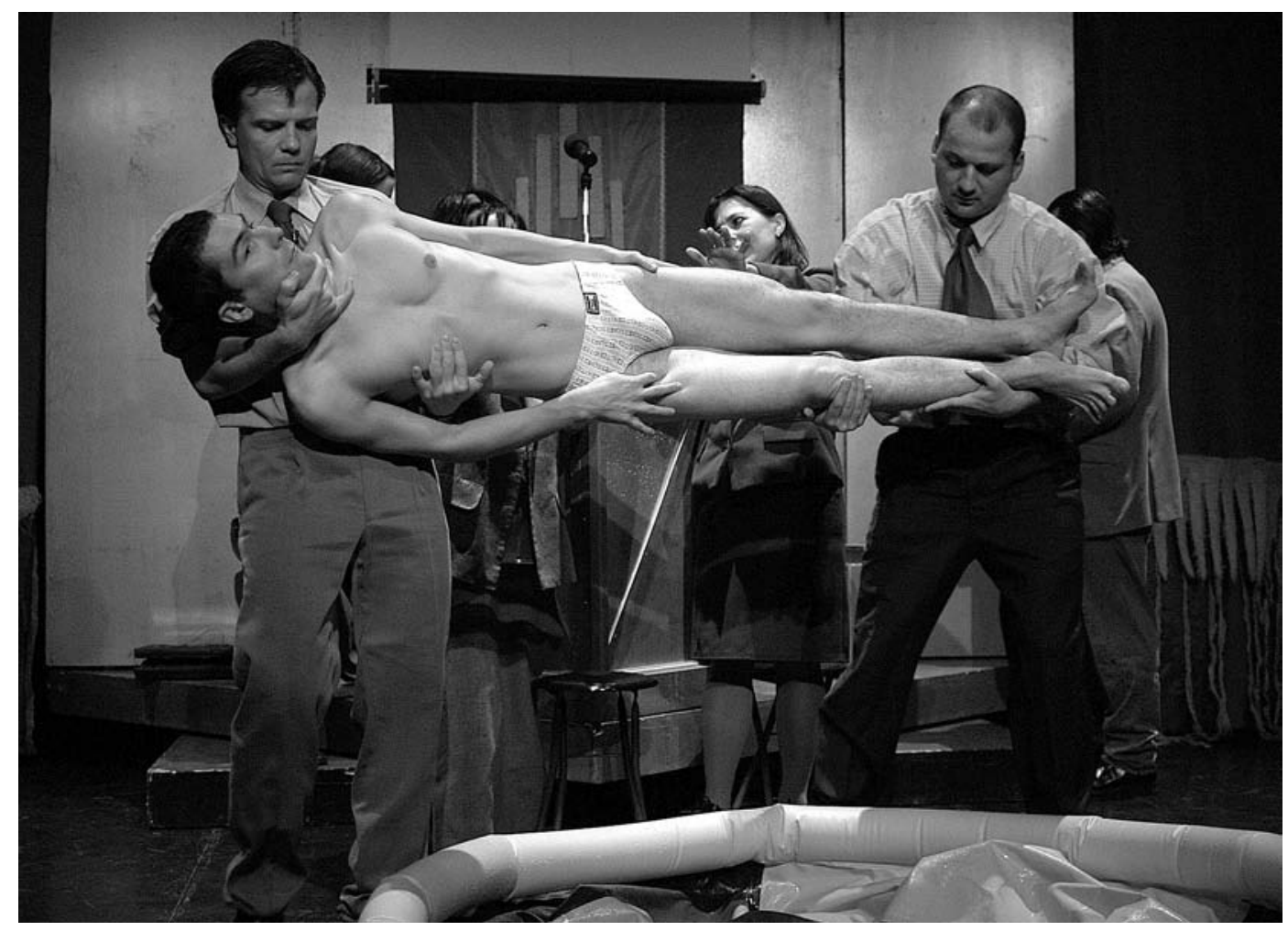

A sehova kapuja

(A porta que abre para nenhum lugar), texto e enc. Pintér Béla, 2000 (frente: Pintér Béla, Hernádi Csaba, Thuróczy Szabolcs, atrás: Balogh Margit, Enyedi Éva, Csatári Margit, Tamási Zoltán), fot. Gäbor Dusa.

a regras menos rígidas. A diferença entre estes dois "sistemas" de teatro reside não só no financiamento, como também na utilização de meios e estilos diversos de apresentação. De entre os teatros experimentais distinguem-se ainda três ou quatro companhias de méritos reconhecidos - entre eles os Pintér Bela -, dos grupos menos reconhecidos e, em consequência disso, ainda menos apoiados. A Pintér Béla e Companhia é actualmente formada por oito actores fixos com percursos de vida bem diferentes, mas que, na sua maioria, não tendo formação universitária, contam já com uma vasta experiência teatral.

0 teatro produzido por Pintér Béla é deliberadamente provocatório. Alguns críticos de teatro na Hungria usam a designação "Pinteriada" quando falam do trabalho dele, dando ênfase às características singulares, únicas, da obra do Pintér na Hungria. Não pertence a correntes estéticas propriamente abstractas, mas obviamente também não se poderia considerar um "clássico". Pintér Béla como dramaturgo não pretende produzir obra literária (não obstante as suas peças terem uma indiscutível qualidade artística), mas sim "obras de vida", "dramas de vida" irónicos, mas de inspiração autêntica, que se constroem de clichés, estereótipos, frescos banais do nosso quotidiano, quer no uso da linguagem, quer na construção das personagens. Alguns críticos afirmam que os seus textos são puramente teatrais, por não poderem existir fora do ambiente do espectáculo, uma vez que tudo neles se concentra no palco. Recorrendo a uma metáfora, poderíamos dizer que as suas peças parecem cadeiras de três pernas: sem o meio teatral, não conseguem apoiarse bem, perdem o equilibrio ${ }^{4}$.

Ao longo das nove peças até agora escritas e encenadas, ganham volume algumas caratceristicas da "Pinteriada" que distinguem este autor dos outros intervenientes do teatro experimental húngaro. 0 seu ponto de partida é obviamente o texto cujo aspecto mais saliente é o de tratar uma temática pessoal numa perspectiva radicalmente subjectiva. Cinco das suas nove peças abordam temas como a perda dos valores tradicionais, a morte do pai, o relacionamento, pai e filho, as religiões, o alcoolismo, a violência doméstica e o sentimento de crise (artística) que parece dominá-lo. Antes de começar a desenvolver um novo projecto, Pintér procura em si o que o perturba, deste modo tentando encontrar
${ }^{4}$ Apesar desta ideia tão recorrente na avaliação do teatro de Pintér, foi recentemente publicada a sua peça A rainha dos bolos na colectânea Ribalta 2005 (coord. Dávid Anna, Budapeste, Editora Magvetö, 2006), o que constitui a sua primeira obra publicada. 
as raizes dos problemas da sociedade no indivíduo. A sua hiper-sensibilidade aos problemas humanos ajuda-o a abordar a realidade de forma profunda, a que não falta uma clarividência por vezes cruel. Por esta razão, nunca se interessou por encenar obras "alheias", temas inventados por outros autores, nem quis trabalhar para teatros institucionais, ainda que já tenha sido convidado por alguns.

Este ano, porém, verificou-se uma excepção: Pintér aceitou o convite da Escola Superior do Teatro e Cinema de Budapeste, tendo chegado a um acordo com a sua direcção. Assim, aceitou trabalhar com os treze finalistas da Escola, dai resultando um extraordinário trabalho em torno da sua peça mais recente Korcsula. Com efeito, fez uma primeira encenação em Budapeste com os treze alunos da Escola Superior, e depois, em Zagreb (Croácia) no Festival Eurokaz, apresentou-a com os oito actores da sua companhia. Uma comparação entre estas duas

${ }^{5}$ Esta divisão é produções torna claro o seu modo de trabalhar, explorando reconhecida pelo próprio autor/ encenador.

0 espectáculo recebeu 0 prémio do Melhor Espectáculo de teatro experimental do ano, atribuido pelos criticos de

${ }^{7}$ Bakony é uma montanha húngara que no século XIX se tornou

famosa por albergar proscritos revolucionários. as virtualidades de cada actor e o modo de recompor a peça para cada espectáculo. Neste caso concreto, ainda, abordava uma temática que é comum à Croácia e à Hungria, o que torna clara a sua pertença a um universo cultural centro-europeu. Apresentava, com efeito, uma forma de modus vivendi típica de países como a Hungria e a Croácia, transmitindo, assim, um ambiente e formas de pensar que caracterizam a vida nesta região.

As obras de Pintér Béla dividem-se em dois grupos em função do tema que elaboram ${ }^{5}$. A primeira peça, ou seja, o ponto de partida da "Pinteriada" foi o Jugo camponês ${ }^{6}$, em 1998, que tocou num tema muito pessoal, vivido pelo autor ou pelos seus familiares mais próximos, dando início a uma série de obras com temática pessoal. Nesta primeira peça, Pintér apresenta o declínio dos valores do nosso quotidiano através de uma boda no campo que

termina em orgia e bacanal, mostrando o esvaziamento completo das tradições dum povo e da vida humana, em geral. Na peça que a seguir escreveu - Hospital Bakony - o autor descreve a situação de sujeição e dependência total em que estão os pacientes hospitalizados e a desmoralização total da sociedade médica. 0 tema pessoal aqui é a morte do seu pai através da qual faz uma forte crítica à sociedade, misturando-a, contudo, de forma surreal, com as histórias famosíssimas de bandidos de aura romântica que se escondiam nessa montanha Bakony. A porta que abre para nenhum lugar trata da ameaça das seitas religiosas que atraem os jovens solitários e infelizes oferecendo-Ihes uma alternativa de vida falsa, que pode por vezes ser mortal. A peça Mata, aparvalha aborda o tema do alcoolismo, a luta do indivíduo contra o vício mais preocupante da Hungria, e que, no fim, naufraga. Mas a sua obra mais emblemática da série de peças com temática pessoal é A rainha dos bolos, que consiste numa confissão muito corajosa da própria infância do autor, revelando um tema social muito melindroso: a violência doméstica.

A outra parte da "Pinteriada" apresenta problemas da sociedade actual. A obra Gyevuska (a palavra significa "menina" em russo) tem como tema central a Segunda Guerra Mundial, o fascismo, a tragédia nacional húngara, cujas consequências são ainda hoje sentidas na sociedade húngara. A ópera do camponês é uma excepção porque evoca uma lenda húngara muito comum do início do século XX, época das grandes emigrações húngaras para as Américas. 0 filho emigra e, depois de ter ganho uma fortuna, volta para a casa dos pais, mas, como eles não o reconhecem, matam-no e roubam-Ihe o dinheiro. 0 tema não parece actual, mas no início do século XX a emigração foi um dos problemas mais graves da sociedade húngara. A penúltima peça, 0 nariz da minha mãe, tem 


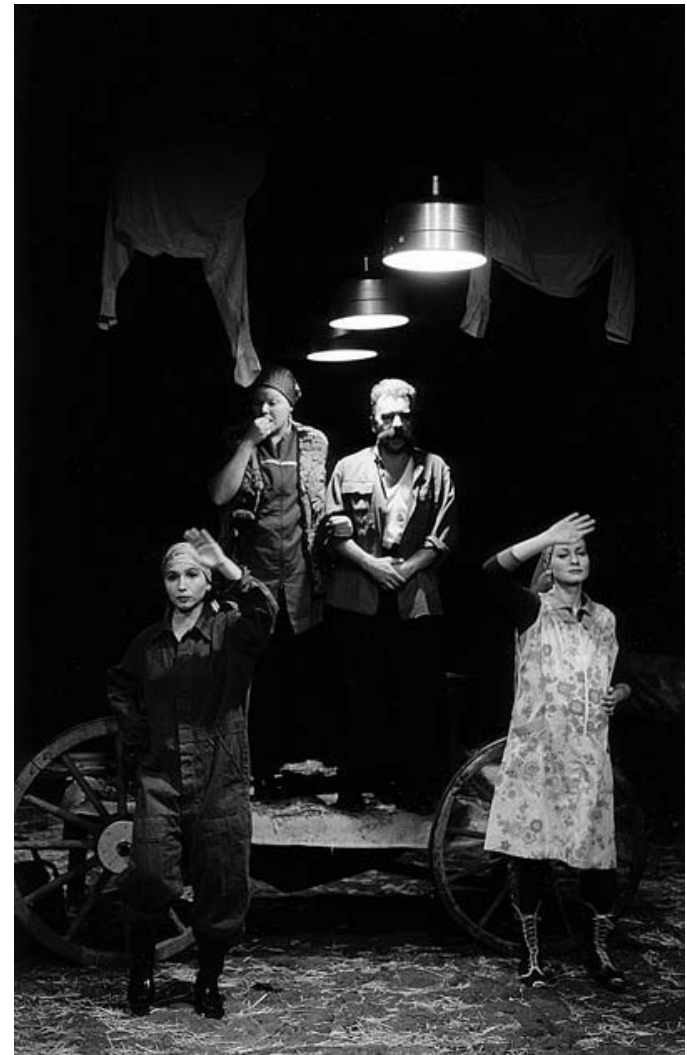

uma história mais complicada. Apresenta um pequeno teatro húngaro na Transilvânia, um lugar muito peculiar na Europa Central, onde vive uma comunidade húngara, que, sendo embora uma minoria, continua a ser expressiva. A acção representa um momento de crise - artística e pessoal - do autor e traz à cena duas figuras estranhas - um doente rico e um charlatão - que querem roubar um rim. Apesar de se constatar no final que se tratou de um pesadelo, não deixa de metaforicamente referir-se à realidade de hoje, revelada como terrivel e imoral. A peça mais recente - Korcsula (nome de uma ilha croata) - traznos um tema aparentemente mais ligeiro: as férias à beiramar num dos lugares preferidos dos húngaros na Croácia. Apesar de a história se reportar a um ambiente de descontracção, nela surgem algumas figuras que vivem as suas tragédias pessoais e que se revelam típicas daquele lugar centro-europeu: o amante que é um turco mafioso, o homem de negócios que, sendo embora homossexual, leva atrelada a sua secretária, o pai - com uma doença terminal - e o filho deficiente mental.

Podemos dizer que Pintér domina todas as áreas no mundo do teatro: é escritor, encenador e actor (segundo os seus críticos, é o melhor actor da sua companhia). 0 seu teatro não é democrático, nem ditatorial: por um lado, é ele o criador "total", mas, por outro, trabalha em estreita ligação com os seus actores, "usando e abusando" das características deles. Pode dizer-se que Pintér lhes rouba a alma, na medida em que, quando cria as suas personagens, aproveita as características, os gestos, os movimentos e os conhecimentos quotidianos dos seus actores. Mas, para além disso, exige-Ihes um estilo muito natural, minimal, sem os elementos típicos do teatro oficial. Não é analítico: é concreto. Neste teatro não há lugar para as improvisações ou para o individualismo, uma vez que o espírito de Pintér se infiltra em tudo.

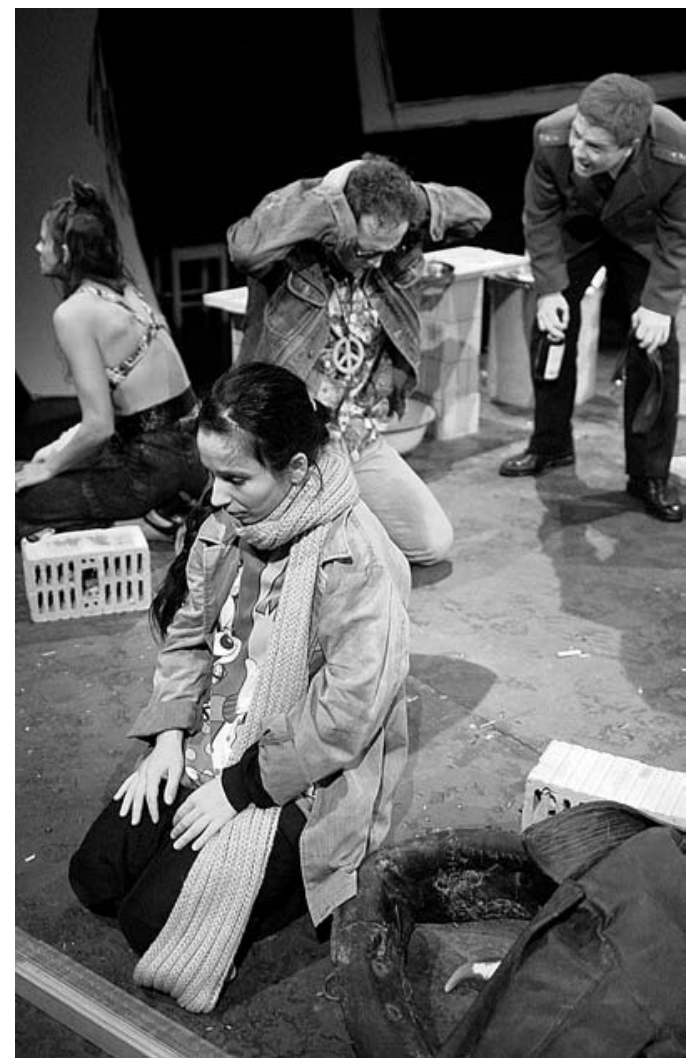

Parasztopera (A ópera do camponês), texto e enc. Pintér Béla, 2001 (Enyedi Éva, Baranyi Szilvia, Tóth József, Hámori Gabriella), fot. Gäbor Dusa.

A sütemények királynöje (A rainha dos bolos), texto e enc. Pintér Béla, 2005 (Csatári Éva, Enyedi Éva, Deák Tamás, Pintér Béla), fot. Gäbor Dusa.
Há ainda um outro elemento básico no teatro de Pintér: todos os actores têm de ter uma vasta experiência em danças tradicionais húngaras, já que em todas as suas peças se encontram elementos do folclore húngaro, misturados muitas vezes com a cultura pop e/ou a música clássica. Vimos isso, por exemplo, na Ópera do camponês, onde os actores tinham de cantar árias, recitativos, duetos e partes corais. 0 espectáculo tornou-se uma verdadeira obra-prima, misturando a música folclórica húngara com a música barroca e algumas canções populares dos anos 70 e 80.0 compositor Benedek Darvas ganhou cinco prémios pela originalidade musical da peça. No espectáculo Gyévuska confrontava-se o folclore com o barroco tardio de Puccini e as canções húngaras típicas da Segunda Guerra Mundial. Deste belíssimo cruzamento de tipos de música surge nas suas "óperas" uma reinterpretação do género musical com um sentido muito irónico.

Outra característica das suas obras é um uso peculiar da linguagem comum. Com efeito, Pintér "rouba" frases, expressões idiomáticas e modismos em voga aos falantes da rua, conferindo às suas peças uma agramaticalidade que torna aquele linguajar uma reprodução autêntica da realidade contemporânea, a que não falta, porém, um traço irónico e enigmático. Outro elemento estruturante do mundo teatral de Pintér é o seu tratamento do tempo, sobrepondo presente e passado, de uma forma que acompanha, de resto, a convivência que tantas vezes no seu teatro se estabelece entre real e irreal.

É esta constante formulação contraditória do seu mundo artístico, este permanente entrecruzar de géneros - tão próprio da sua professada pós-modernidade - que torna Pintér Bela um criador único que vive intensamente a sua vida através da arte que cria, como se nada mais valesse a pena fazer para além do teatro. 